\title{
Speed Control of Brushless DC Motor based on Fractional Order PID Controller
}

\author{
Ameer L. Saleh \\ Department of Electrical Engineering \\ University of Basrah
}

\author{
Adel A. Obed \\ Department of Electrical Engineering \\ University of Basrah
}

\begin{abstract}
Increasing the methods of order calculus for Fractional Order Proportional Integral Derivative (FOPID) controller leads to a wide applications for this type of controller in control systems. A closed loop speed control for BrushLess Direct Current (BLDC) motor with FOPID controller runs the motor very close to the reference speed, provides a good performance and robustness compared with a corresponding system using conventional PID controller. In this paper, the BLDC motor is modeled and simulated in Matlab/Simulink for speed control strategy. A DC link speed control strategy is proposed and implemented. The FOPID speed controller parameters $(\mathrm{Kp}, \mathrm{ki}, \mathrm{kd}, \lambda, \mu)$ are optimized by genetic evolutionary programming module. The effectiveness of the proposed speed control is verified through simulation. The control system is extra tested under a conditions of some motor parameters perturbations. The simulation results reveal a flexible and stable control strategy.
\end{abstract}

\section{General Terms}

Speed control of brushless de motor

\section{Keywords}

BLDC motor, modeling and simulation, fractional order PID controller.

\section{INTRODUCTION}

The BLDC motor has been widely used in many applications such as, industrial automation, medical, electric traction, consumer, aerospace, road vehicles, aircraft, military equipment, hard disk, etc. It has the advantages of high reliability, good efficiency, high power density, lower weight, low maintenance requirements, and wide speed range. On the other hand, the developments in power semiconductor technology, power electronic technology and microprocessors/logic ICs make the BLDC motor gaining popularity[1,2]. BLDC motors do not have brushes for commutation, Instead they are electronically commutated using three phase bridge inverter with feedback rotor position. The rotor position feedback is necessary for starting and providing proper commutation to turn on the inverter. The BLDC motor consists of permanent magnet rotor and distributed stator winding which are wound such that the back emf's is trapezoidal. The phase current, typically quisi - squar shape, is synchronized with the back emf to produce constant torque at constant speed. The BLDC motor is operated when two phases are ON at any time while the third phase is floating.

Different simulation models have been presented to analyze the performance of BLDC motor and also to give precise value of torque which is related to current and back-emf
[3-5]. Basically, two methods, sensor and sensorless, are used to detect the rotor position. The BLDC motor is multivariable and non linear system [6-8], so it is difficult to get accurate and reliability control performance result for BLDC motor using conventional control linear method.

In this paper a fractional order PID controller is used to get more accurate and high reliability than conventional method. The proposed controller is used to control the duty cycle of the DC-DC converter by PWM technique, while the proposed rotor position scheme used to firing the provide commutation sequence to the inverter. The proposed method gives and accurate and flexible speed control and can reduce effectively commutation torque ripple within a wide speed range.

\section{MODELING OF BLDC MOTOR}

The three-phase BLDC motor has a three windings in the stator supplied from an inverter which converts a DC voltage to a three-phase voltages with frequency corresponding to rotor position. The rotor has a permanent magnet poles mounted on the shift. The mutual inductance between the stator and the rotor has a trapezoidal shape which produce a trapezoidal back emf in stator winding[9-11]. Figure 1 shows the equivalent circuit of a three-phase, Y connected BLDC motor driven by a three phase inverter.

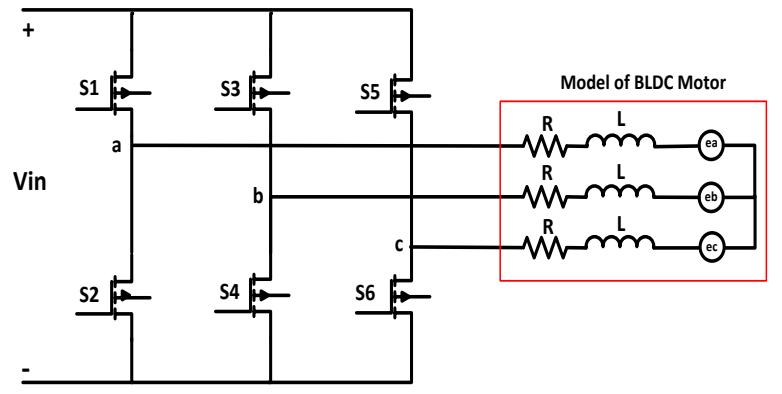

Fig 1: Equivalent circuit of brushless de motor

The stator phase voltage equations can be written as

$$
\begin{aligned}
& v_{\mathrm{a}}=\mathrm{R} i_{a}+(\mathrm{L}-\mathrm{M}) \frac{\mathrm{d}}{\mathrm{dt}} i_{a}+\mathrm{e}_{\mathrm{a}} \\
& v_{\mathrm{b}}=\mathrm{R} i_{b}+(\mathrm{L}-\mathrm{M}) \frac{\mathrm{d}}{\mathrm{dt}} i_{b}+\mathrm{e}_{\mathrm{b}} \\
& v_{\mathrm{c}}=\mathrm{R} i_{c}+(\mathrm{L}-\mathrm{M}) \frac{\mathrm{d}}{\mathrm{dt}} i_{c}+\mathrm{e}_{\mathrm{c}}
\end{aligned}
$$


where $\mathrm{V}_{\mathrm{abc}}$ are the phase voltages, $\mathrm{i}_{\mathrm{abc}}$ are the phase stator currents, $\mathrm{R}$ is the stator resistance of each phase; $L$ is the stator self inductance per phase and $\mathrm{M}$ is the mutual inductance. The induced back emf depends on the rotor position and can be given as follows:

$\mathrm{e}_{\mathrm{a}}=\frac{\mathrm{k}_{\mathrm{e}}}{2} \mathrm{w}_{\mathrm{m}} \mathrm{F}\left(\theta_{\mathrm{e}}\right)$

$\mathrm{e}_{\mathrm{b}}=\frac{\mathrm{k}_{\mathrm{e}}}{2} \mathrm{w}_{\mathrm{m}} \mathrm{F}\left(\theta_{\mathrm{e}}-\frac{2 \pi}{3}\right)$

$e_{c}=\frac{k_{e}}{2} w_{m} F\left(\theta_{e}-\frac{4 \pi}{3}\right)$

where $\mathrm{w}_{\mathrm{m}}$ is the rotor speed, $\mathrm{k}_{\mathrm{e}}$ is the back - emf constant and $\theta_{\mathrm{e}}$ is the electrical rotor angle. The electrical rotor angle is equal to the mechanical rotor angle $\theta_{\mathrm{m}}$ multiplied by the number of poles $\mathrm{P}$ :

$$
\theta_{\mathrm{e}}=\frac{\mathrm{p}}{2} \theta_{\mathrm{m}}
$$

The function $\mathrm{F}(\theta \mathrm{e})$ gives the trapezoidal waveform of the back -emf. One period of this function can be written as follow:

$$
\mathrm{F}\left(\theta_{\mathrm{e}}\right)=\left\{\begin{array}{lc}
1 & 0<\theta_{\mathrm{e}}<\frac{2 \pi}{3} \\
1-\frac{6}{\pi}\left(\theta_{\mathrm{e}}-\frac{2 \pi}{3}\right) & \frac{2 \pi}{3}<\theta_{\mathrm{e}}<\pi \\
-1 & \pi<\theta_{\mathrm{e}}<\frac{5 \pi}{3} \\
-1+\frac{6}{\pi}\left(\theta_{\mathrm{e}}-\frac{2 \pi}{3}\right) & \frac{5 \pi}{3}<\theta_{\mathrm{e}}<2 \pi
\end{array}\right.
$$

The developed torque $\mathrm{T}_{\mathrm{e}}$ can be expressed as

$\mathrm{T}_{\mathrm{e}}=\frac{\mathrm{k}_{\mathrm{t}}}{2}\left[\mathrm{~F}\left(\theta_{\mathrm{e}}\right) \mathrm{i}_{\mathrm{a}}+\mathrm{F}\left(\theta_{\mathrm{e}}-\frac{2 \pi}{3}\right) \mathrm{i}_{\mathrm{b}}+\mathrm{F}\left(\theta_{\mathrm{e}}-\frac{4 \pi}{3}\right) \mathrm{i}_{\mathrm{c}}\right.$

where $\mathrm{k}_{\mathrm{t}}$ is the torque constant. The equation of mechanical part is represented as follows :

$$
T_{e}-T_{L}=j \frac{d w_{m}}{d t}+\beta w_{m}
$$

where $T_{L}$ is the load torque; $j$ is the rotor inertia; $\beta$ is the friction constant. The BLDC motor equations(1-10) can be rewritten in a compact state space model as follows:

$$
\begin{aligned}
{\left[\begin{array}{c}
\mathrm{i}_{\mathrm{a}}^{\prime} \\
\mathrm{i}_{\mathrm{b}}^{\prime} \\
\mathrm{w}_{\mathrm{m}}^{\prime} \\
\theta_{\mathrm{m}}^{\prime}
\end{array}\right]=\left[\begin{array}{cccc}
-\frac{\mathrm{R}}{\mathrm{L}} & 0 & 0 & 0 \\
0 & -\frac{\mathrm{R}}{\mathrm{L}} & 0 & 0 \\
0 & 0 & \frac{\beta}{\mathrm{j}} & 0 \\
0 & 0 & 1 & 0
\end{array}\right]\left[\begin{array}{c}
\mathrm{i}_{\mathrm{a}} \\
\mathrm{i}_{\mathrm{b}} \\
\mathrm{w}_{\mathrm{m}} \\
\theta_{\mathrm{m}}
\end{array}\right] } \\
+\left[\begin{array}{ccc}
\frac{2}{3 \mathrm{~L}} & \frac{1}{3 \mathrm{~L}} & 0 \\
\frac{-1}{3 \mathrm{~L}} & \frac{1}{3 \mathrm{~L}} & 0 \\
0 & 0 & \frac{1}{\mathrm{j}} \\
0 & 0 & 0
\end{array}\right]\left[\begin{array}{c}
\mathrm{v}_{\mathrm{ab}}-\mathrm{e}_{\mathrm{ab}} \\
\mathrm{v}_{\mathrm{bc}}-\mathrm{e}_{\mathrm{bc}} \\
\mathrm{T}_{\mathrm{e}}-\mathrm{T}_{\mathrm{L}}
\end{array}\right]
\end{aligned}
$$

\section{FRACTIONAL ORDER CONTROLLER 3.1- Fractional Order Calculus}

Fractional order calculus is a space of mathematical analysis where the mathematicians deal with the derivative or integral of a function to non - integer ( fractional ) order. Fractional calculus evaluates $\left(\frac{d y^{n}}{d t^{n}}\right), \mathrm{n}$ fold Integrals. where $\mathrm{n}$ is fractional. There are many definitions use to describe the fractional order function [12]. The well established definitions include the Cauchy integral formula, the Grunwald - Letnikov definition, the Riemann - Liouville definition. The Riemann - Liouville definition is the most frequently used definition in fractional-order calculus, in which the fractional order integration is defined as:

$$
\mathrm{aDt}^{-\varphi} \mathrm{f}(\mathrm{t})=\frac{1}{\Gamma(\varphi)} \int_{\mathrm{a}}^{\mathrm{t}}(\mathrm{t}-\tau)^{\varphi-1} \mathrm{f}(\tau) \mathrm{d} \tau
$$

where $a \mathrm{Dt}^{-\varphi}$ is the differintegral operator. It is the combination of differentiation and integration operation commonly used in fractional calculus. Reimann- Liouville definition for a $\mathrm{D} \mathrm{t}^{-\varphi}$ is

$\mathrm{a} \mathrm{D} \mathrm{t}^{-\varphi}= \begin{cases}\frac{\mathrm{d}^{\alpha}}{\mathrm{dt}^{\alpha}} & \alpha>0 \\ 1 & \alpha=0 \\ \int_{\mathrm{a}}^{\mathrm{t}}(\mathrm{d} \tau)^{-\alpha} & \alpha<0\end{cases}$

where $\varphi$ represents the real order of the differintegral $(0<\varphi<1)$, a is the initial time distance, $\Gamma(\varphi)$ is the well-known Euler's gamma function and $t$ is the parameter for which the differintegral is taken. The Laplace transform of the fractional derivative of $f(t)$ is given by:

$$
£\left[D t^{\varphi} f(t]=s^{\varphi} £[f(t)]-\sum_{k=1}^{n} s^{k}\left[D t^{\varphi-k-1} f(t)\right] t=0\right.
$$

\section{2 - Fractional Order PID controller}

Fractional order control systems are described by fractional order differential equations. Fractional calculus allows the derivatives and integrals to be any real number $[13,14]$. The FOPID, $\mathrm{PI}^{\lambda} \mathrm{D}^{\mu}$, controller is an extension of conventional PID controller where a new integral factor $\lambda$ and a new derivative factor $\mu$ have fractional values add more flexibility and make the system less sensitive to parameters changes. The differential equation of the $\mathrm{PI}^{\lambda} \mathrm{D}^{\mu}$ controller can be described as follows:

$u(t)=K_{p} e(t)+K_{i} D^{-\lambda} e(t)+K_{d} D^{\mu} e(t)$

where $\mathrm{e}(\mathrm{t})$ is the error between the measured process output variable and a desired set point and $u(t)$ is the control output. Thus the transfer laplace function of the controller becomes:

$\mathrm{G}(\mathrm{s})=\mathrm{K}_{\mathrm{p}}+\mathrm{K}_{\mathrm{i}} \mathrm{S}^{-\lambda}+\mathrm{K}_{\mathrm{d}} \mathrm{S}^{\mu}$

Figure.2 Shows the block diagram of FOPID controller. The conventional PID can be obtained by setting $\lambda=\mu=1$. Moreover, when $\lambda=1$ (or 0 ) and $\mu=0$ (or 1) a normal PI (or PD) controller can be obtained as shown in Fig.3. The fractional order $\mathrm{PI}^{\lambda} \mathrm{D}^{\mu}$ controller generalizes the integer 
order PID controller and expands it from a point to a plane.

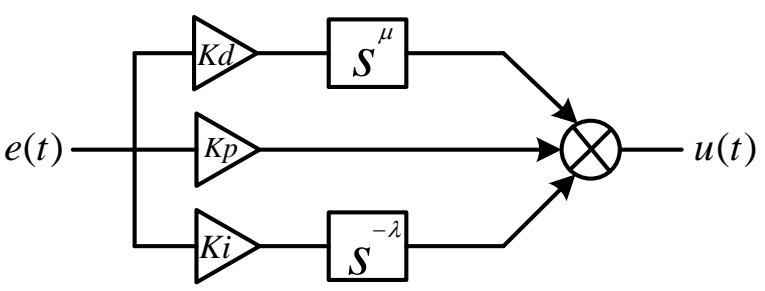

Fig 2: Fractional order PID controller

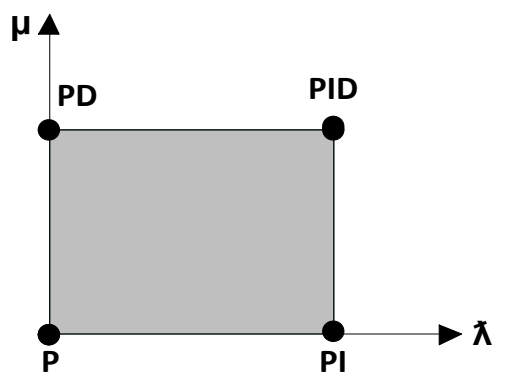

Fig 3: Generalized FOPID controller

\section{3- Genetic Evolutionary Algorithm (GEA)}

The Evolutionary Algorithm (EA) is an optimization algorithm used to solve a problem and finding optimal solutions. Evolutionary algorithms are divided into different types, the known are genetic algorithms, evolutionary programming, evolution strategies and genetic programming. The structure of a generic evolutionary algorithm is shown as a flow chart in Fig.4.

At the beginning of the computation a number of the individuals representing the candidate solutions are randomly initialized. Those candidate solutions represent the current population $\mathrm{P}(\mathrm{t})$. An objective function is then evaluated for these individuals to obtain the fitness for each individuals. If the optimization criteria are not met, the creation of new generation will start. The individuals that have high fitness are more likely to be selected as a parent to generate the offspring for a new generation. Best parents are recombined to produce offspring. This process is called Crossover. Crossover operator is applied to the mating pool with the hope that it creates a better offspring. After a crossover, offspring will be subjected to mutation. The mutation randomly reforms an offspring to generate new variants. The fitness of the offspring is then computed. By inserting the offspring into the population, new generation $\mathrm{P}(\mathrm{t}+1)$ is created. The cycle is performed until the maximum number of generations elapse or desired level of fitness is reached[12].

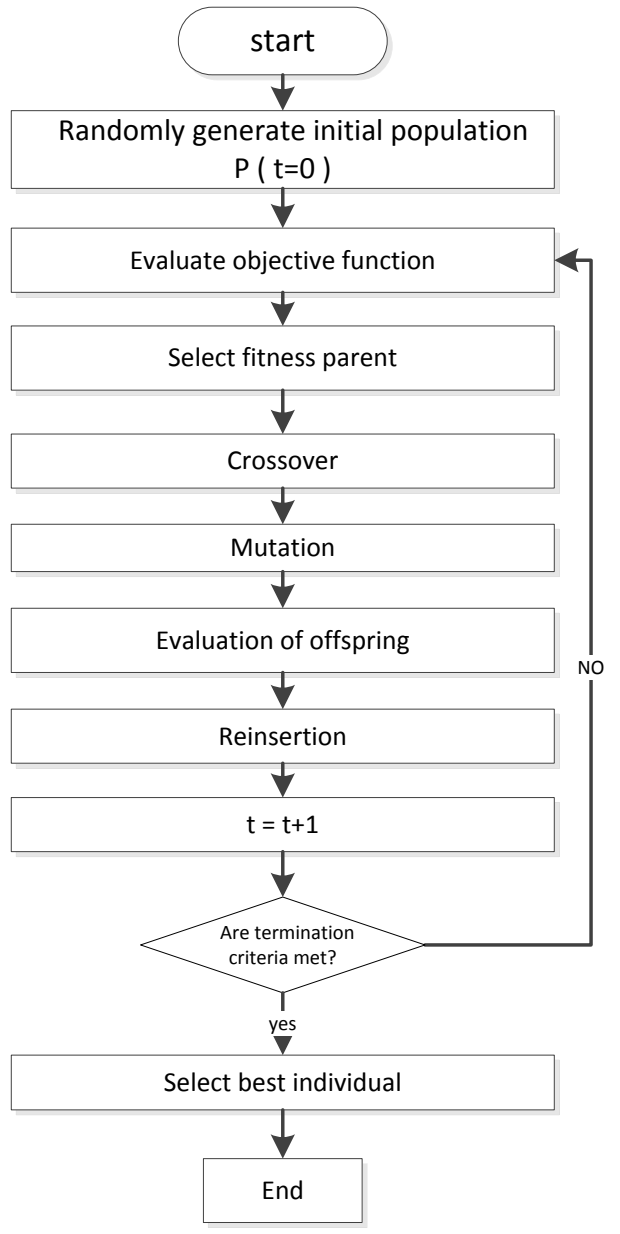

Fig 4: Structure of an evolutionary genetic algorithm

\section{BLDC MOTOR DRIVE FOR SPEED CONTROL}

The drive system consists of a BLDC motor, three phase inverter, DC-DC converter and controller. The speed of BLDC motor is directly proportional to its terminals voltages. The terminals voltages are changed using DCDC converter connected at the input of the inverter. The proposed control system consists of proposed rotor position scheme, which detect the rotor speed, to provide proper commutation sequence to the inverter and FOPID controller to control the duty cycle of the DC-DC converter using PWM technique. The schematic block diagram for the drive system of brushless dc motor is shown in Fig.5. The simulink model is shown in Fig.6. The brushless DC motor can be built according to the mathematical modeling in equations [1-10].

The inverter can be implemented by look up table that takes in the value of the dc-source voltage and the firing signals from the control block. The back emf's can be calculated by using look up table by the equation [8], where the position signal is passed to look up table model and multiplied by rotational speed, after that the signal of back emf can be obtained, while the FOPID controller is simulated as a fractional PI controller, $\mu=0$, using equation[15]. 
In this model only one closed loop used to control the speed where the actual speed is measured and compared with the reference speed to find the error signal speed which is supplied to the FOPID controller as shown in Fig.7. The FOPID controller is utilized to determine the duty cycle of PWM signal according to the speed error. The PWM signal is supplied to the DC-DC converter which gives the voltage amplitude required to maintain the desired speed.

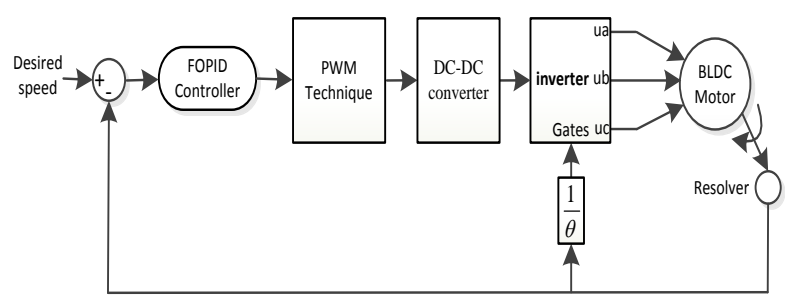

Fig 5: The drive system of BLDC motor

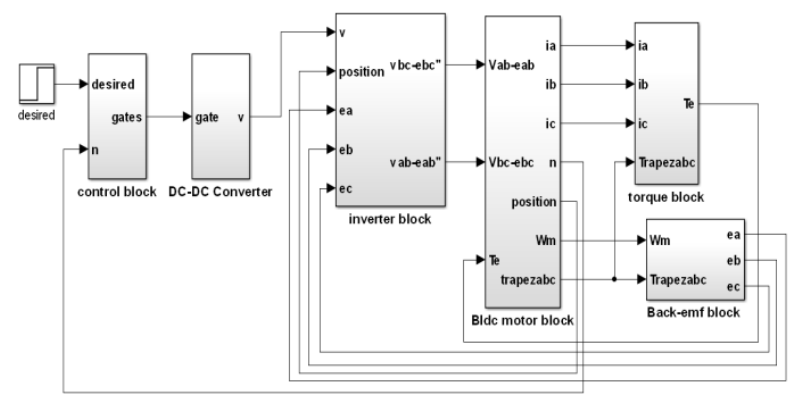

Fig 6: Simulink model of BLDC motor drive

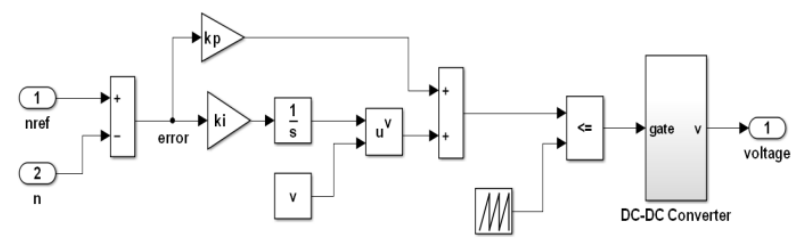

Fig 7: Simulink of speed control strategy

\section{SIMULATION RESULTS}

The simulink model with FOPI controller for the speed of BLDC motor is developed in Matlab using genetic evolutionary algorithm module to set the parameters $\left(K_{P}, K_{I}, \lambda\right)$ which give the desired control of speed. Fig.(7) shows the changing in the control parameters $\left(K_{P}, K_{I}, \lambda\right)$ during the optimization steps. After 329 steps of optimization, the optimal values of the proposed FOPID controller are $\mathrm{K}_{\mathrm{P}}=0.3, \mathrm{~K}_{\mathrm{I}}=3, \lambda=1.26$ and $\mu=0$. as shown in Fig.7. The speed is set at 2000rpm zero initial load torque. A step change in the load torque from 0 to $2 \mathrm{~N} . \mathrm{m}$ is applied at time $0.6 \mathrm{Sec}$, then the performance of the BLDC motor are drawn and compared with the same system using conventional PI controller.

The last controller parameters are optimazed the same GEA. Fig. 8 shows the speed of the BLDC motor during starting and step change in load torque for FOPID and conventional controller. Fig.9-12 show the developed torque, phase A current and phase back emf respectively for the same starting and loading conditions. From these results, it can be shown that the motor performance is better with FOPID controller.

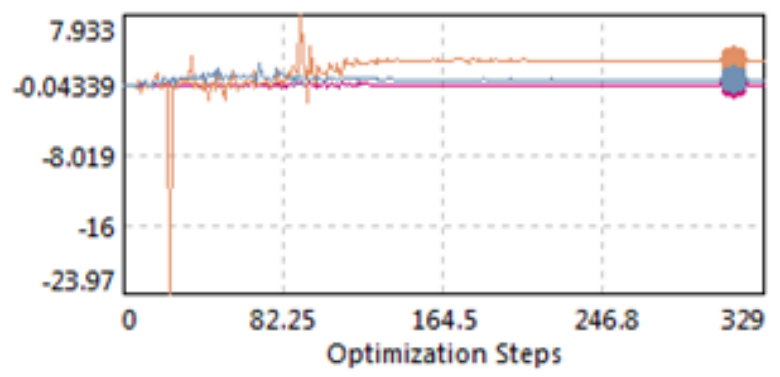

Fig 8: optimization parameter of FOPI using EA

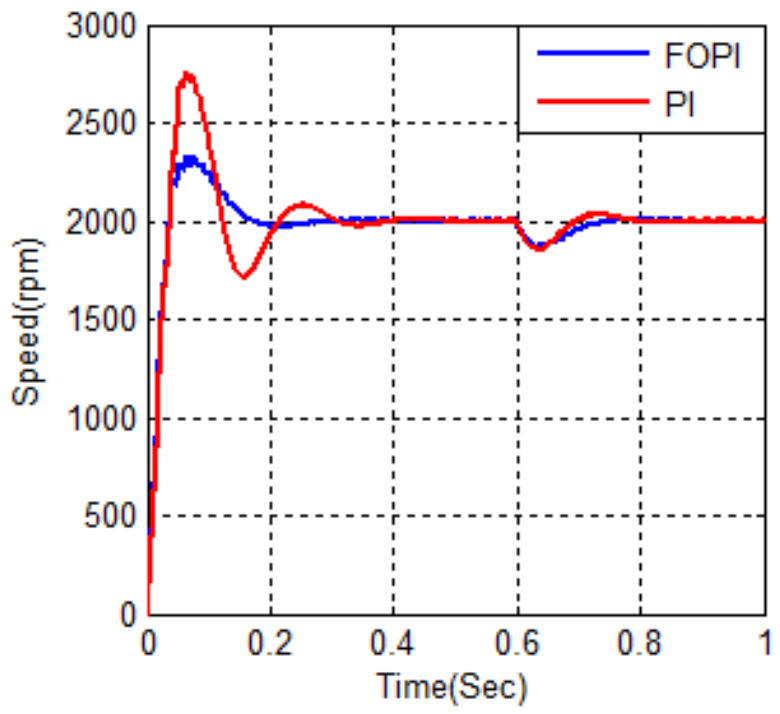

Fig 9: Speed characteristics under all conditions 

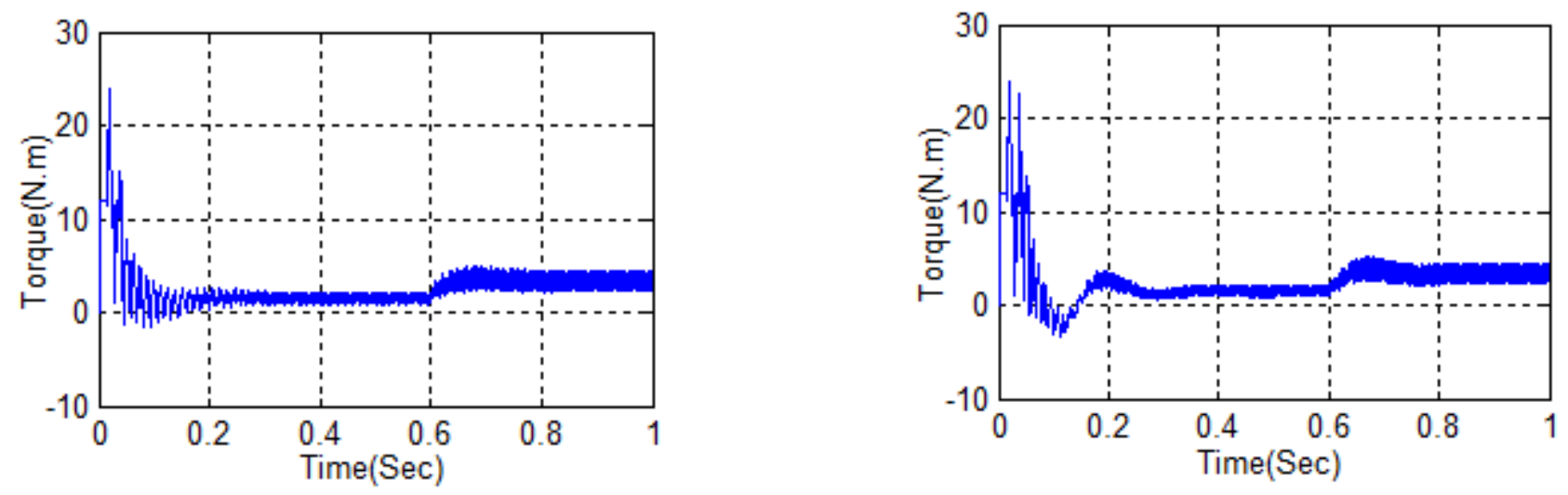

Fig 10: Torque characteristics of BLDC motor (a) FOPI controller (b) conventional PI controller
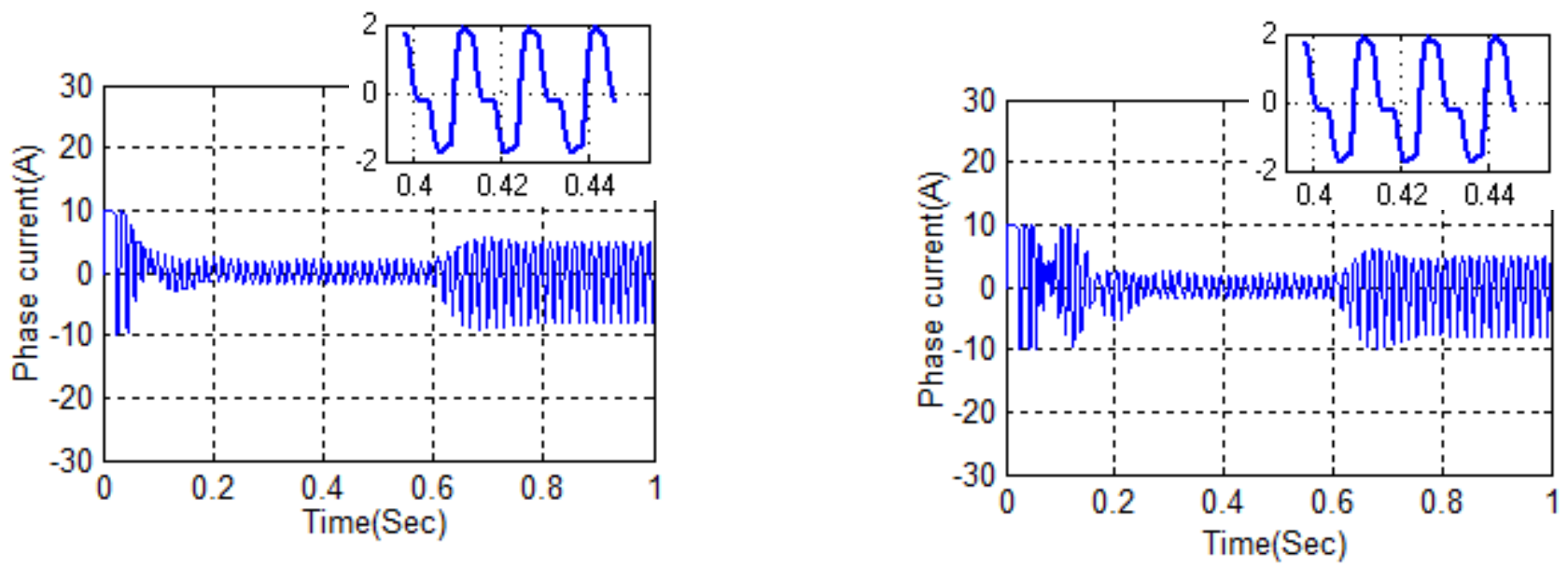

Fig 11: Phase A current of BLDC motor (a) FOPI controller (b) conventional PI controller
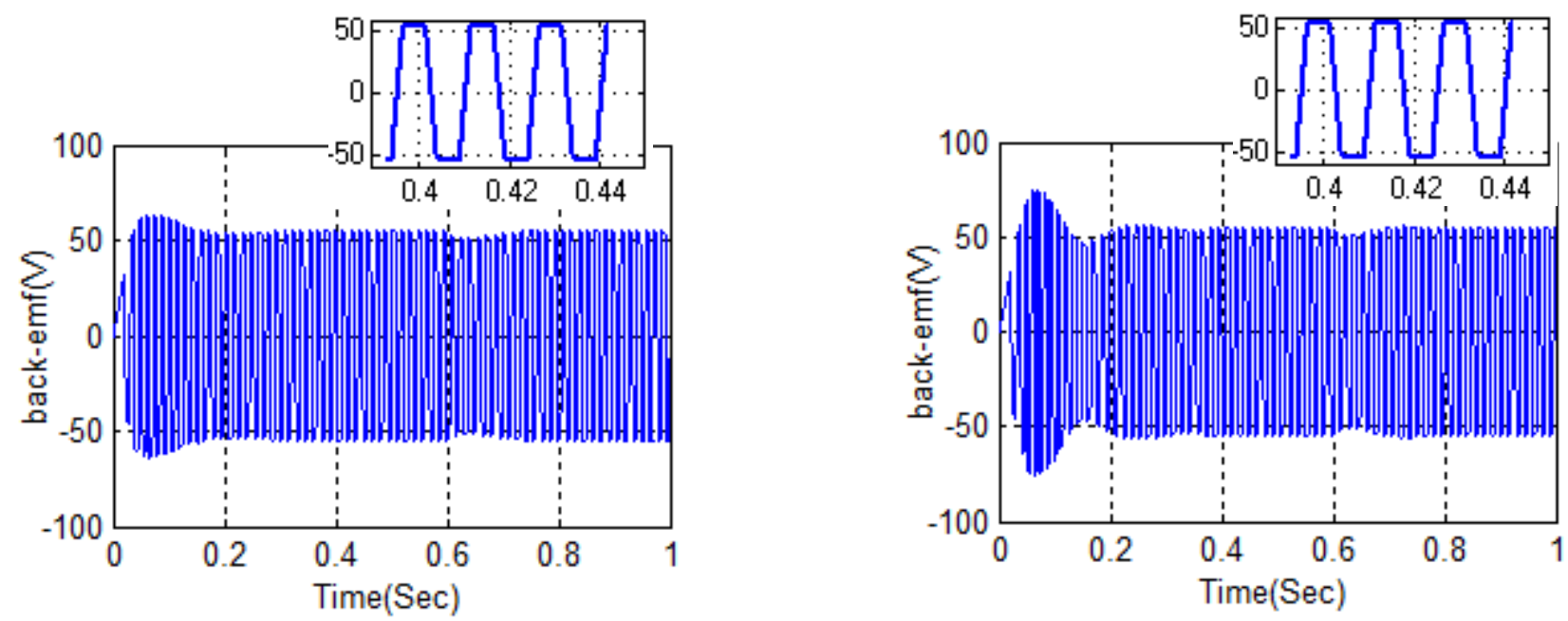

Fig 12: Phase A current of BLDC motor (a) FOPI controller (b) conventional PI 


\section{Robustness}

In order to test the robustness of the proposed method, the effect of sudden change for full load torque have studied on the performance of the torque control and speed changes.

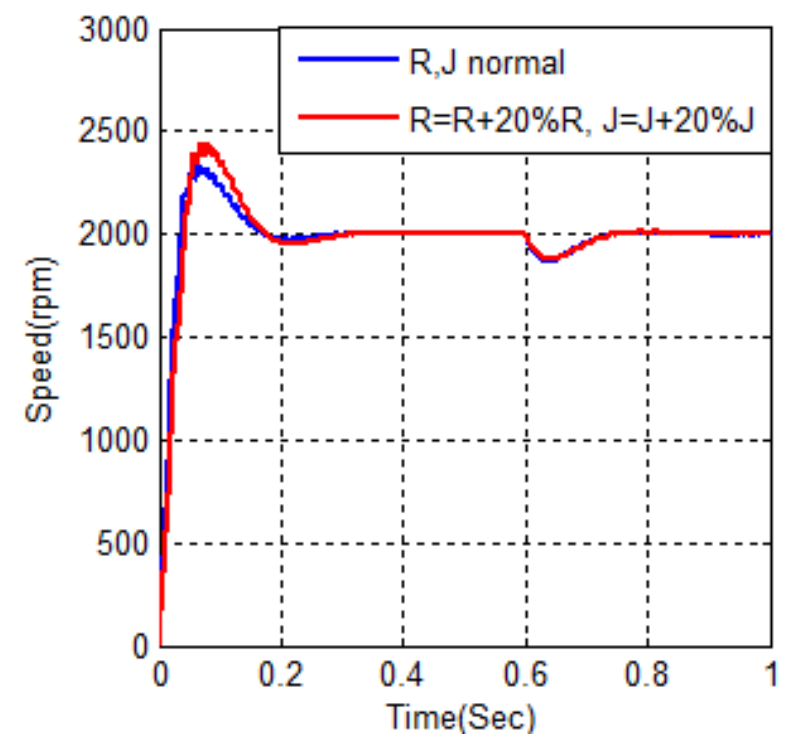

Fig 13: effect changes the resistance and inertia on the speed

\section{CONCLUSION}

In this paper, Fractional order PI controller is used to add more flexible to the speed control BLDC motor system. FOPI parameters are optimal tuning using Evolutionary Algorithms. From the simulation results, it can be concluded that the proposed FOPID controller improves the overshoot, the rising time, settling time, steady state error and provides flexibility and robust stability as compared to the same system using conventional PID controller.

\section{REFERENCES}

[1] Viond KvSingh patel, A. K. Pandey, " Modeling and Simulation of Brushless Dc motor using Pwm control Technique" International Journal of Engineering Research and Applications, Vol.3, Issue 3, May-Jun 2013, PP.612-620.

[2] Neethu U. and Jisha V. R., " Speed Control of Brushless DC Motor: A Comparative Study", IEEE International Conference on PowerElectronics, Drivesand Energy Systems, 978-1-4673-45088/12/\$31.00, Dec 2012.

[3] Padmaraja Yedamale, “ Brushless DC (BLDC) Motor Fundementals", AN885, 2003 Michrochip Technology Inc.

[4] S. Rambabu, " Modeling and Control of A BRUSHLESS DC Motor",Master of Thesis In Power Control and Drives Technology, National Institute of Technology Rourkela,2007.
[5] A. Tashakori, M. Ektesabi and N. Hosseinzadeh, " Modeling of BLDC Motor with Ideal Back-EMF for Automotive Applications, Proceedings of the World Congress on Engineering, Vol II, July 6 - 8, 2011, London, U.K.

[6] José Carlos Gamazo - Real*, Ernesto Vázquez Sánchez and Jaime Gómez - Gil, " Position and Speed Control of Brushless DC Motors Using Sensorless Techniques and Application Trends " Department of Signal Theory, Communications and Telematic Engineering, University of Valladolid, Sensors, PP.6901-6947, June-July 2010.

[7] Milan Tomić, "Sensorless control of brushless DC electromotor" Diploma thesis in Electrical power Engineering, University of Belgrade, Feb 2004.

[8] Maohua Zhang, Changliang Xia, Yang Tian, Dan Liu, Zhiqiang Li, " Speed Control of Brushless DC Motor Based on Single Neuron PID and Wavelet Neural Network ", IEEE International Conference on Control and Automation, Guangzhou, CHINA - May 30 to June $1,2007$.

[9] Stefan Baldursson, "BLDC motor modeling and control - a MATLAB/ SIMULINK implementation ”, Master Thesis in Electrical Power Engineering, Chalmers University of Technology, May 2005, Gothenburg, Sweden.

[10] Kaliappan, E. and C. Chellamuthu, " Simplified Modeling, Analysis and Simulation of Permanent Magnet Brushless Direct Current Motors for Sensorless Operation" IEEE American Journal of Applied Sciences,Vol.9, Issue7, PP. 1046-1054, ISSN 1546-9239,2012.

[11] GencerC.andGedikpinar M., "Modeling and Simulation of BLDCM Using MATLAB/SIMULINK", IEEE Journal of Applied Sciences,Vol.6, Issue3, PP.688691,ISSN 1812-5654,2006.

[12] Ammar A. Aldair and Weiji J. Wang," Design of Fractional Order Controller Based on Evolutionary Algorithm for a Full Vehicle Nonlinear Active Suspension Systems ", International Journal of Control and Automation, Vol. 3, No.4, December 2010.

[13] Ankit Rastogi, Pratibha Tiwari," Optimal Tuning of Fractional Order PID Controller for DC Motor Speed Control Using Particle Swarm Optimization ", International Journal of Soft Computing and Engineering (IJSCE), ISSN: 2231-2307, Volume 3, Issue 2, May 2013.

[14] Rinku Singhal, Subhransu Padhee, Gagandeep Kaur , "Design of Fractional Order PID Controller for Speed Control of DC Motor", International Journal of Scientific and Research Publications, Volume 2, Issue 6, June 2012. 